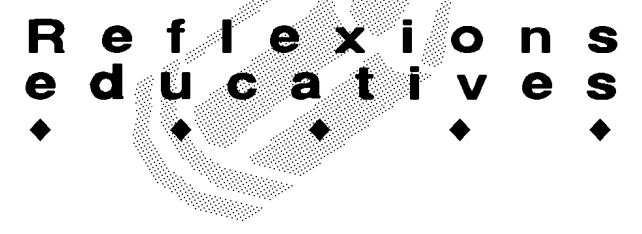

\title{
EDUCACIÓ POLÍTICA MÉS QUE MAI
}

\author{
Antoni Santisteban Fernández. Àrea de Didàctica de les Ciències Socials. URV
}

L'educació política és un coneixement social que ha d'estar basat en la racionalitat, la comunicació i l'acció social. No és tan sols l'ensenyament de les institucions polítiques, de la seva història i del seu funcionament, és educació crítica en la democràcia. Donar una opinió o emetre un judici és fer política (ARENDT, 1997), com també ho és arriscar-se a participar. El desenvolupament de les capacitats per a la intervenció social demana el convenciment que podem modificar el nostre món. Per a Suchodolski (1983) "somos tal como somos, pero también tal como seremos. Lo real es tanto lo que existe como lo que es posible". Hem de tornar a pensar el futur com a aprenentatge (SANTISTEBAN, 1995).

Una reflexió sobre l'educació política ha de partir de l'anàlisi de la societat, dels canvis socials que estan afectant la concepció de la democràcia, ha de situar-se dins el currículum de ciències socials i ha de definir una proposta que contempli per què, què i com ha d'ensenyarse la democràcia i la intervenció social (SANTISTEBAN, 1999).

\section{Canvis socials i participació democràtica}

Diferents autors coincideixen a assenyalar una sèrie de canvis socials que han modificat les maneres de percebre el món, i en conseqüència, també les formes en què les persones es relacionen i conviuen. En el context de la "societat del coneixement", que jo m'estimo més qualificar com a "societat de la informació i de l'espectacle" (Umberto Eco parla de la "ideologia de l'espectacle"), la cultura democràtica es fa imprescindible, com també ho és el pensament crític. L'educació i el pensament crític són interdependents en una societat democràtica $\mathrm{o}$, com a mínim, el pensament crític és la finalitat més important de l'educació. L'educació política és ensenyament per a la democràcia i és educació crítica. Analitzem alguns canvis socials que han de fernos replantejar els nostres objectius educatius.

a) La globalització és una de les característiques del nostre temps, tant de l'activitat econòmica com de les relacions polítiques, de la informació, les comunicacions i la tecnologia. Hi ha una inseguretat creada por la manca de control dels intercanvis i influències econòmiques i culturals, alienes als propis interessos i tradicions. $\mathrm{Ha}$ variat el medi social de l'alumnat, que ara inclou espais presents als mitjans de comunicació, però la intervenció social i la democràcia poden practicar-se de manera real en l'espai més pròxim. És a partir d'aquesta idea que podem plantejar la necessitat d'un diàleg entre allò que és local i allò que és global als programes educatius.

b) La flexibilitat, la rendibilitat i la competitivitat són característiques imposades per la societat postindustrial, en la producció i en el consum de la ciutadania. La promoció d'organitzacions flexibles, mòbils i creatives es pot considerar un procés positiu, però el seu objectiu autèntic és respondre a la urgència de la competitivitat. L'educació política aporta l'anàlisi de les estructures socials, d'associacions o grups, quins són els seus objectius, com s'organitza el poder. És molt important tornar a pensar en els nens i nenes, en els nois i noies, com a ciutadans, com a consumidors, usuaris de serveis, receptors d'informació, amb drets i deures, futurs votants $i$ actuals actors de la democràcia en el seu medi familiar, a la seva ciutat o al seu país.

c) El relativisme i la diversitat caracteritzen un canvi en la racionalitat. Ja no existeixen veritats absolutes. El relativisme no és un obstacle per a l'aprenentatge, sinó una realitat educativa que ha de conduir cap a l'anàlisi de valors i la comprensió d'opinions divergents. El relativisme ha facilitat l'acceptació de la diversitat. Totes les persones som diferents, fet que dóna lloc a la diversitat de pensaments i de cultures, però tractar la diversitat ignorant les desigualtats és fer una anàlisi falsejada de la realitat social. L'educació política s'ha de basar en el respecte a la diferència, però també en la denúncia de les desigualtats i injustícies. Els drets humans, la cooperació i la solidaritat són aprenentatges fonamentals.

d) Les transformacions en les relacions humanes donen lloc a una sensació de inestabilitat en les organitzacions socials $i$ en les relacions interpersonals. Els canvis en les relacions familiars i en el temps de dedicació a la pròpia satisfacció estan donant lloc, segons Hargreaves (1996), al naixement del jo il-limitat, és a dir, a un narcisisme personal que transcendeix el simple egocentrisme. Des de l'educació política s'ha de treballar el procés d'autoconeixement, a distingir les seves possibilitats i les seves limitacions personals. Però aquest procés no és individual, sinó que ha de fer-se en interacció amb altres persones, en el grup, formant els conceptes de llibertat, igualtat i responsabilitat. 


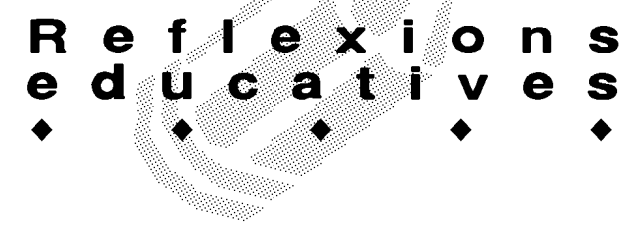

e) L'acceleració del canvi tecnològic i científic està provocant una gran incertesa sobre el futur. Els canvis no són analitzats de manera crítica, sinó assumits de manera mecànica. L'autonomia personal es torna dèbil davant les imposicions tecnològiques. D'altra banda, la societat produeix un augment d'informació de tot tipus, sense que existeixi un aprenentatge crític per a la selecció d'aquesta informació. Hi ha un gran desenvolupament de la simulació, que afavoreix la mitificació de la imatge. L'omnipresència d'alguns mitjans com la televisió a la vida quotidiana de les persones està provocant canvis en el procés de socialització primària, afectant les funcions de la família i de l'escola. Un dels efectes més preocupants per a l'educació democràtica és la desmobilització de la ciutadania (TEDESCO, 2002). Per aquest motiu s'ha de defensar la participació democràtica com un deure de la ciutadania.

f) A la nostra societat s'ha produït una variació de les concepcions del temps i de l'espai. La causa s'ha de buscar en els avenços de la tecnologia comunicativa i dels transports, i en les possibilitats de la simulació. L'ensenyament ha d'ajudar a comprendre el temps i l'espai no tan sols com a coordenades objectives, sinó com a conceptes socials que es veuen afectats pels canvis en les relacions de la ciutadania. L'anàlisi de la gestió del temps i de l'espai ens ajuda a comprendre l'organització social i les relacions de poder.

j) La incertesa davant el futur és conseqüència d'alguns aspectes analitzats: relativisme, canvis tecnològics, transformacions en les relacions humanes o la dificultat per comprendre el temps i l'espai. Han variat les nostres expectatives sobre el futur. La nostra visió del futur es veu avui dia superada per una sensació d'ansietat, provocada por la pèrdua de confiança en tres elements essencials del nostre passat més immediat: la ciència i la tecnologia com a dominadores de la natura, l'ordre socioeconòmic com a subministrador del benestar i l'organització política com a sistema de participació per a la intervenció social. L'educació política ha de lluitar contra aquesta última constatació.

\section{Poblemes de l'educació democràtica}

Per combatre el desànim que provoca la pèrdua de la confiança en l'organització política i en la intervenció social, hem de aprofundir en alguns problemes de l'educació democràtica, més o menys actuals.

a) Existeix una contradicció entre la valoració social de l'educació política i la desconfiança que genera la seva pràctica (SANTISTEBAN, 1993). És cert que pocs ensenyaments presenten un nivell de consens tan important com els valors democràtics, i en canvi, pocs ensenyaments són tan discutits com l'educació política, per la por a la manipulació o a l'adoctrinament ideològic.

b) La pressió de les institucions públiques obliga de vegades a tractar qüestions relacionades amb la història d'una institució o la promoció d'algun organisme públic. En nom de la democràcia s'elaboren materials per a l'escola que no responen a un programa coherent d'educació política, sinó que són per a l'autopromoció o la propaganda política.

c) Certes tradicions religioses afavoreixen una educació per a la submissió al poder establert, dificultant el desenvolupament de la idea de canvi sobre el nostre destí i les nostres condicions de vida, amb el diàleg i la cooperació (DELVAL, 1996).

d) També hem d'evitar l'adoctrinament nacionalista, que, com qualsevol adoctrinament, no és tolerable en l'ensenyament democràtic. L'educació política ha d'afavorir l'equilibri entre la definició de la pròpia identitat i la valoració positiva de l'alteritat.

e) En l'educació política existeix una contradicció entre els valors democràtics ensenyats i el que el sistema capitalista reclama: "En este aspecto no podemos sino constatar la importante contradicción que en la actualidad se está produciendo entre les finalidades políticas que se le atribuyen a la escuela en les sociedades democráticas (equidad, igualdad, solidaridad y desarrollo humano) y las exigencias del mercado laboral (excelencia, formación vocacional, competitividad individual)" (PÉREZ GÓMEZ, 1998).

f) Som actors i espectadors. No podem oblidar que formem part del món social, com també forma part l'escola: "La cuestión no radica en que no exista un mundo social estable para ser conocido, sino que el conocimiento de ese mundo contribuye a su carácter cambiante e inestable" (GIDDENS, 1993). Amb les nostres accions contribuïm a fomentar o a contrarestar un determinat model de societat.

\section{Quina educació política?}

En aquesta proposta es contemplen set apartats generals d'un possible currículum d'educació política.

a) Autoconeixement. L'educació política ha de afavorir el desenvolupament de l'autonomia personal, l'equilibri entre l'autoconcepte i l'autoestima, així com la capacitat per valorar les opinions d'altres persones sobre el nostre comportament. Un aspecte important d'aquest aprenentatge és la capacitat autoreguladora de les pròpies actuacions, factor essencial en la construcció del concepte de llibertat i en el de responsabilitat social.

b) Llibertat i participació. El sentit de la política és ben senzill, és la llibertat. Però aquesta llibertat no té un significat únic de llibertat personal, d'independència 0 d'autonomia, sinó que també és, com a concepte polític 


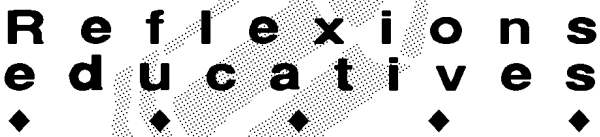

democràtic, llibertat de participació (CAMPS, 1993), la qual cosa significa acceptar la responsabilitat de col-laborar i de decidir.

c) Solidaritat. La participació democràtica comporta la preocupació pels assumptes públics o comuns, així com un cert grau d'altruisme. Podem afirmar que sense solidaritat no existeix la democràcia, ja que aquesta és un tipus d'organització social i de sistema polític on sempre existeixen desigualtats.

d) Resolució de problemes socials. Els problemes no són exclusius de les matemàtiques, de la física o de la química; en la formació del pensament social la resolució de problemes és fonamental. En l'educació política els problemes són la base de l'acció social, han de tenir en compte les experiències de l'alumnat $i$ han de ser rellevants.

e) Prejudicis i judicis. Els prejudicis formen part de la vida quotidiana de les persones i de la seva cultura política. Les persones no podem viure sense prejudicis, no cal evitar-los, sinó analitzar-los, racionalitzar-los i transformar-los en judicis conscients. La capacitat de construcció coherent dels judicis és una peça fonamental de la cultura democràtica.

f) Organització social. Un element clau de l'educació política és la conceptualització del poder, com es justifica, com s' estructura i com es relaciona amb altres conceptes com llibertat, igualtat o justícia. D'altra banda, avui dia el poder adquireix tonalitats variades; els mitjans de comunicació, per exemple, poden arribar a tenir un gran poder.

g) En aquest sentit és imprescindible la perspectiva històrica en l'estudi de les organitzacions i de la política, per evitar les visions ahistòriques i immobilistes de la democràcia. En últim terme, la visió dels canvis socials en el passat i des del present han d'ajudar a la construcció crítica del futur.

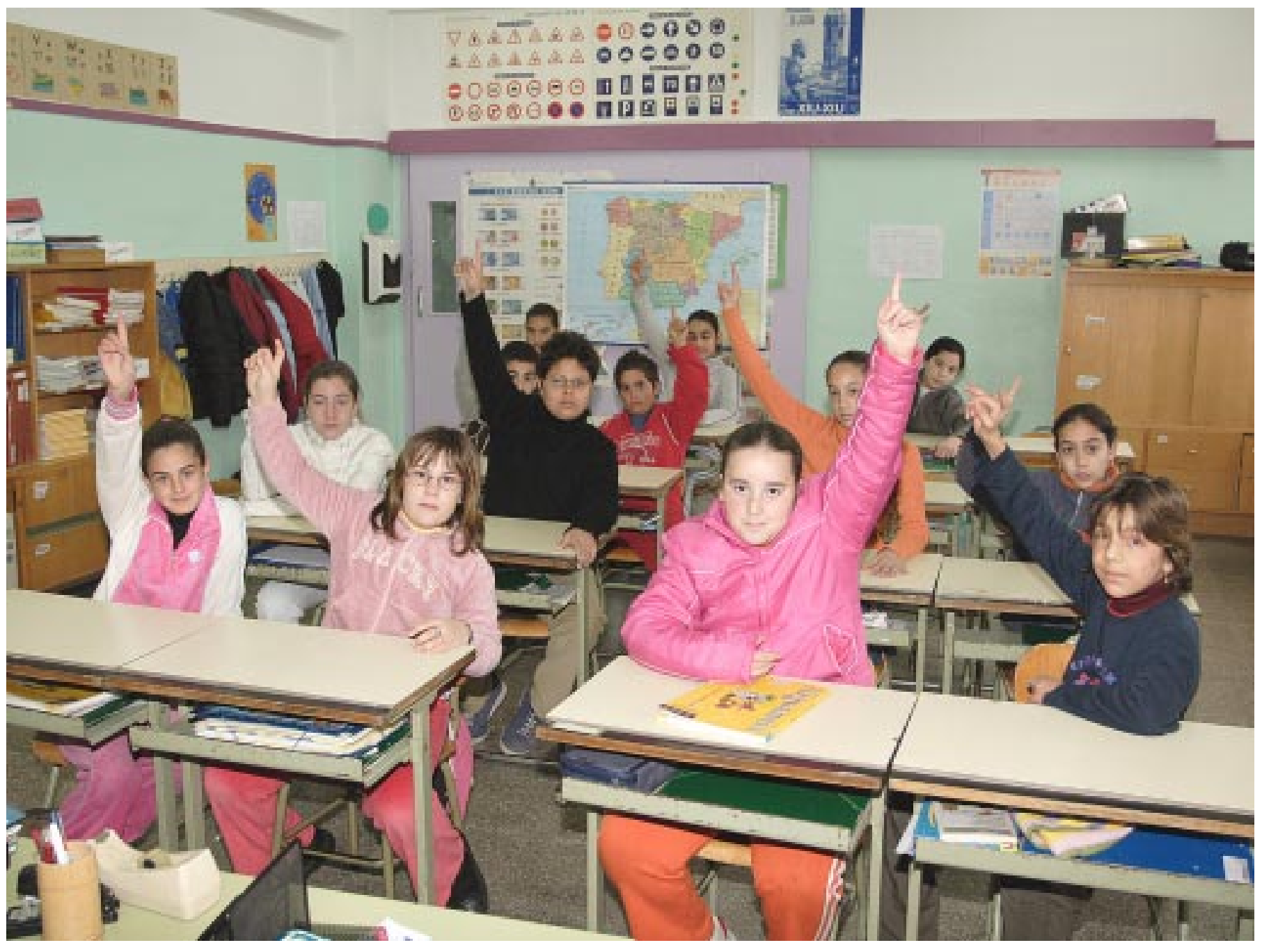




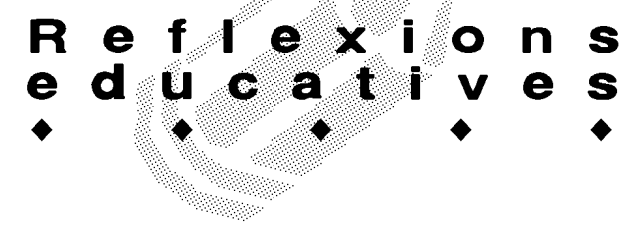

\section{Com organitzar el context comunicatiu de l'aula?}

Educar per a la democràcia és ensenyar a dibuixar un camí que hem d'inventar cada cop, que mai ens sembla del tot just, que mai es camina sense contratemps.

a) Comunicació. La comunicació que es dóna a l'aula és el baròmetre que ens indica quin model educatiu es gestiona al seu interior, per regular les relacions o les interaccions entre les diferents persones que hi conviuen. Aquesta comunicació és en gran part oral i en gran part simbòlica. La comunicació és l'indicador de la cultura democràtica de la convivència escolar. Què ha de ser la comunicació? Des de l'educació política, un procés d'intercanvi de maneres de percebre el món social, d'inquietuds $\mathrm{i}$ ideals, i per compartir coneixement sobre l'organització i la convivència, que possibilita un aprenentatge social crític de la democràcia.

b) Diversitat. La comunicació no és solament el reconeixement de l'altre, de la seva cultura o dels seus valors morals o estètics, és el diàleg amb una persona que organitza de manera distinta a la meva els elements de la vida i de la convivència, i que dóna respostes diferents a preguntes comunes.

c) Racionalitat. En primer lloc, fa falta afavorir la construcció de l'opinió de l'alumnat sobre els problemes socials que l'afecten, així com la seva contrastació a partir del debat. En segon terme, fa falta aprendre a valorar la intencionalitat de les interpretacions, de tal manera que puguem comprendre les opinions d'altres persones. Finalment, és necessari saber exposar els nostres judicis sobre problemes, fets o comportaments socials.

d) Pensament crític i creatiu. El pensament crític no es pot separar del pensament creatiu. És cert que allò que és crític pot no ser creatiu, però allò que és creatiu no pot deixar de ser crític. La capacitat creadora és essencial en la construcció de la democràcia. Cada persona té la llibertat $\mathrm{i}$ el deure de plantejar alternatives a la realitat social. (CORTINA, 1997).

e) Conflicte. Sense l'acceptació, la descripció i el tractament dels conflictes no existeix democràcia. Si amaguem el conflicte a l'alumnat, estem creant la por a la controvèrsia. L'educació política té la funció d'ensenyar a resoldre els conflictes. El conflicte requereix l'aprenentatge de la negociació, com la defensa dels interessos personals o de grup i la capacitat de fer concessions o de renunciar a determinades pretensions. Parts essencials en la resolució de conflictes són l'empatia, el debat i la cooperació. Posar-nos en la pell de l'altre, dialogar sobre el conflicte, debatre sobre els nostres judicis, les nostres expectatives, oferir l'esperança de la col-laboració per superar els problemes. Des dels conflictes personals als de política internacional, els conflictes tenen una sèrie d'elements comuns, que ens porten a considerarlos continguts que es poden ensenyar, però que també ens fan reflexionar sobre la seva gran dificultat. Malgrat tot, aquest ha de ser un dels objectius de l'educació política, com a educació per a la vida.

\section{Un nou concepte de democràcia}

La democràcia és un procés sempre inacabat. És un instrument de comunicació i de convivència (PAGÈS i SANTISTEBAN, 1994). La llibertat és un dret i un deure, el de participar i intervenir en la societat per millorar-la, des d'una actitud crítica. La creativitat és el pensament divergent $\mathrm{i}$ les propostes alternatives. Pensar que podem influir en el nostre futur és un objectiu irrenunciable.

\section{Referències bibliogràfiques}

ARENDT, H. ¿Qué es la política? Ed. Paidós/ICE de la UAB. Barcelona. 1997.

CAMPS, V. Paradojas del individualismo. Ed. Crítica. Barcelona. 1993.

CORTINA, A. Ciudadanos del mundo. Hacia una teoría de la ciudadanía. Ed. Alianza. Madrid. 1997.

DELVAL, J. Los fines de la educación. Ed. Siglo XXI. Madrid. 1996.

ECO, U. Cinco escritos morales. Ed. Lumen. Barcelona. 1998.

GIDDENS, A. Consecuencias de la modernidad. Ed. Alianza. Madrid. 1993.

HARGREAVES, A. Profesorado, cultura y postmodernidad (Cambian los tiempos, cambia el profesorado). Ed. Morata. Madrid. 1996.

PAGÈS, J.; SANTISTEBAN, A. Democràcia iparticipació.

Ed. Eumo. Barcelona. 1994.

PÉREZ GÓMEZ, A. La cultura escolar en la sociedad neoliberal. Ed. Morata. Madrid. 1998.

SANTISTEBAN, A. Ensenyar politica o fer política, ¿és aquesta la qüestió? «L'Avenç », 174 (1993) 38-40.

SANTISTEBAN, A. Democràcia, creativitat i aprenentatge de futurs. "Guix», 210 (1995) 13-18.

SANTISTEBAN, A. Educació política: per què, que i com. Quan dos per dos no són quatre. «Perspectiva Escolar», 234 (1999) 19-30.

SANTISTEBAN, A. Formación de la ciudadanía i educación política, a VERA, M.I.; PÉREZ i PÉREZ, D. Formación de la Ciudadanía: Las TICs i los nuevos problemas. XV Simposio Internacional de Didáctica de les Ciencias Sociales. AUPDCS. Alicante. 2004.

SUCHODOLSKI, B. La pedagogía de la esperanza. «Educación y Sociedad», 2 (1983) 25-36.

TEDESCO, J.C. Educación y ciudadanía paritaria, a IMBERNÓN, F. (coord.), Cinco ciudadanías para una nueva educación. Ed. Graó. Barcelona. 2002. 